\title{
Perceptions of Psychological Domain of Quality of Life in Patients with Diabetes Mellitus
}

\author{
Živana Gavrićc , Dragana Grujić-Vujmilović \\ Department of Social Medicine, Medical Faculty of Banjaluka University, Banjaluka, B\&H (Bosnia and Herzegovina) \\ Email: zgavric210@gmail.com
}

Received 23 April 2014; revised 29 May 2014; accepted 12 June 2014

Copyright (C) 2014 by authors and Scientific Research Publishing Inc.

This work is licensed under the Creative Commons Attribution International License (CC BY). http://creativecommons.org/licenses/by/4.0/

c) (i) Open Access

\section{Abstract}

Introduction: Adaptation to changes that occur with diabetes mellitus is often accompanied by a variety of negative emotional responses, including anger, guilt, frustration, denial, and loneliness. Objective: The aim of this study was to assess psychological domain of quality of life for people with diabetes mellitus in relation to some of the socio-demographic variables. Methods: The study included 150 patients with diabetes mellitus from October 2011 until June 2012 year, using the questionnaire for quality of life of the World Health Organization (WHOQOL-BREF). Results: Mean score for psychological health domain was $56.28( \pm 14.88)$, without statistically significant difference in relation to sex and with a statistic significant difference decreased with increasing of age $(F=6.715, p=0.000)$ and increased with the level of education $(F=7.958, p=0.000)$. Negative emotions, such as blue mood, despair, anxiety, depression were present in almost $1 / 2$ of the respondents, "often" $(32.7 \%)$, "very often" $(11.3 \%)$ and "always" $(4.0 \%)$ without statistically significant difference in relation to gender, age and level of education. Discussion: Mean scores for psychological health domain were lower in older and less educated patients. Conclusion: Negative feelings were present in all patients indicating the need for preventive action to soften and reduce these negative feelings.

\section{Keywords}

Diabetes Mellitus, Quality of Life, Psychological Domain

\section{Introduction}

Diabetes mellitus is a chronic condition and as such is characterized by long duration and slow progression [1].

\footnotetext{
${ }^{*}$ Corresponding author.
}

How to cite this paper: Gavrić, Ž. and Grujić-Vujmilović, D. (2014) Perceptions of Psychological Domain of Quality of Life in Patients with Diabetes Mellitus. Open Journal of Preventive Medicine, 4, 489-498. 
Living with a chronic disease imposes many threats and challenges to patients such as dealing with uncertainties about their present and future physical capacities, sustaining relationships with family and friends, dealing with pain and other symptoms, and concerns about their abilities to resume their former lifestyle [2] [3].

Diabetes mellitus is a demanding disease that affects a person's health-related quality of life, a person's ability to function and to desire satisfaction from doing so [4]-[6]. People with diabetes are constantly reminded of the disease on a daily basis: they have to eat carefully, exercise, test their blood glucose and based on the result decide when to schedule their next meal or medication. Furthermore, they often have to stop and check for symptoms of hypo or hyperglycemia as well as deal with the fears of the possibility of complication of the disease [7].

Many patients with diabetes mellitus may become chronically frustrated, discouraged, and/or enraged with a disease that often does not seem to respond to their best efforts, because the demands of diabetes care can have a potent impact on mood, both short-term and long-term. Frequent hypoglycemic episodes can be exhausting, debilitating, discouraging and potentially quite frightening, and the disease is often accompanied by a variety of negative emotional responses, including anger, guilt, frustration, denial, and loneliness [8].

Diabetes-related distress among people with diabetes is associated with suboptimal self-management [9] [10], which may then lead to more complications and worse blood glucose control, compared with patients who are not distressed [10] [11]. Necessary adjustments to daily life to help manage diabetes and long-term concerns can lead to people feeling that diabetes has a negative impact on many aspects of their daily life, which can impact on their emotional well-being [12].

Measuring the impact of chronic disease on quality of life of the patient is important because physiological measurements and laboratory parameters do not provide sufficient insight into the patient's psychological status and satisfaction, which is in the perception of the patient more important than objective indicators [13]. In clinical practice, a phenomenon that is often present is that two patients who meet the same clinical criteria have significantly different outcome assessment of emotional aspects of quality of life or activities of daily living [13] [14].

Therefore, tools for evaluating the quality of patients' lives are more used to monitor the clinical effects of health care interventions and planning costs of the health system [15].

Quality of life of diabetic patients decreases with presence of mental problems such as depression [16], so prevention and early detection of depression and other mental problems seem to be important in diabetic patient for prevention of excess decrease in quality of life in these patients [17].

Assessment of quality of life is also important in prevention programs.

In determining targeted prevention programs to improve the quality of life as well as their implementation, it is necessary to include a larger number of experts that would help overcome the problem of the individual, the family and the community that are expected to support those suffering from ill [18].

\section{Objective}

The aim of this study was to assess psychological domain of quality of life for people with diabetes mellitus in relation to some of the socio-demographic variables.

\section{Materials and Methods}

The study was carried out between October 2011 and June 2012 at the Clinic for the Endocrinology, Diabetes and Metabolic Diseases of the Clinical center in Banja Luka, Bosnia and Herzegovina. This survey included 150 patients treated for diabetes mellitus, type 1 or type 2 .

Patients who met the inclusion criteria and who visited the clinic during this period participated in the study. Criteria for exclusion from the study were: patients younger than 18 years and patients older than 75 years, patients whose diagnosis were set less than a year ago, pregnant women, patients who had both diabetes mellitus and some other disease from the group of diseases of endocrine glands and metabolic disorders, patients who had rheumatoid inflammation of the joints, patients with malignant neoplasm's and patients with psychiatric disorder. Patients on hemodialysis were also excluded from the study.

With the approval of the ethics committee of healthcare facilities and the patients gave written consent to participate in research. Questionnaires were filled by the doctor in the form of interviews with patients.

To assess the quality of life we used the questionnaire on the quality of life of the World Health Organization 
(WHO), WHOQOL-BREF, and the Serbian version [19]. The WHOQOL-BREF assesses quality of life through four specific domains which includes physical health, psychological well being, social relationships and environment. It also contains two items that are examined separately (individual's overall perception of quality of life and individual's overall perception of health). The psychological domain include six items assessing areas such as positive and negative feelings, cognitive functions, self esteem, body image and physical appearance, personal beliefs.

In the questionnaire were set a time frame of two weeks within which a person evaluates their quality of life. Responses were given on Likert scales of 1 - 5, with 1 being the least agreement and 5 indicates the highest agreement with the particles. Responses are transformed into points, in two steps, and the points for the domain are within of the scale 0 - 100. A higher score represents a higher ("better"), a smaller number of points represents lower ("worse") level of functioning [20].

Questionnaire also contained some questions about socio-demographic status (sex, age, education level).

Statistical analysis was performed using SPSS, version 17.0 and statistical software R, version 2.15.1. Descriptive statistics were calculated for all study variables with parameters: frequency, mean, standard deviation, score, tests of significance (chi-square test, $\mathrm{t}$ test, Men-Whitney test, Kruskal-Wallis test) with a significance level of $\mathrm{p}<0.05$.

\section{Results}

The study included 150 patients (87 male or $58 \%$, and female 63 or $42 \%$ ). More than $2 / 3$ (78\%) were aged over 50 years and the average age was 55.95 years $( \pm 12.36)$. The highest percentage of patients were with secondary (48\%), followed by primary (20\%) and high (18.67\%) level of education (Table 1).

The mean score for the domain of psychological health was $56.28( \pm 14.88)$, with a higher mean score for males (57.28 \pm 14.77$)$ patients, but without statistically significant difference $(t=0.969, p=0.334)$ compared to female respondents $54.89( \pm 15.03)$. With the increase of age of patients mean score for this domain declines so it was the highest in patients younger than 30 years of $70.83( \pm 8.33)$ and in the $30-39$ age 68.75 years $( \pm$ 12.13), with a statistically significant difference $(F=6.715, \mathrm{p}=0.000)$ compared to the patients older than 60 years of 51.34 ( \pm 14.66). With the increase of the level of education mean scores for psychological domain of quality of life also increase, so that they are lowest in patients with unfinished primary school $44.79( \pm 13.58)$, with a statistically significant difference $(\mathrm{F}=7.958, \mathrm{p}=0.000)$ compared to patients with higher education 60.27 ( \pm 13.39) (Table 2).

\begin{tabular}{|c|c|c|}
\hline \multirow{2}{*}{ Variables } & \multicolumn{2}{|c|}{ Diabetes mellitus $(\mathrm{N}=150)$} \\
\hline & $\mathrm{N}$ & $\%$ \\
\hline \multicolumn{3}{|l|}{ Gender } \\
\hline Male & 87 & 58.00 \\
\hline Female & 63 & 42.00 \\
\hline \multicolumn{3}{|l|}{ Age group } \\
\hline$<30$ & 8 & 5.33 \\
\hline $30-39$ & 10 & 6.67 \\
\hline $40-49$ & 15 & 10.00 \\
\hline $50-59$ & 55 & 36.67 \\
\hline$\geq 60$ & 62 & 41.33 \\
\hline Min & 21 & \\
\hline Max & 75 & \\
\hline $\mathrm{Me} \pm \mathrm{SD}$ & $55.95 \pm 12.36$ & \\
\hline \multicolumn{3}{|l|}{ Level of education } \\
\hline Unfinished primary & 20 & 13.33 \\
\hline Primary & 30 & 20.00 \\
\hline Secondary & 72 & 48.00 \\
\hline High/college & 28 & 18.67 \\
\hline
\end{tabular}


Table 2. Mean psychological domain scores in diabetic patients by gender, age and level of education.

\begin{tabular}{|c|c|c|}
\hline Variables & $\begin{array}{l}\text { Mean psychological domain scores } \\
(\text { (Me } \pm \text { SD) }\end{array}$ & $\begin{array}{l}\text { Test and level of } \\
\text { significance }\end{array}$ \\
\hline Total & $56.28( \pm 14.88)$ & \\
\hline \multicolumn{3}{|l|}{ Gender } \\
\hline Male & $57.28 \pm 14.77$ & \multirow{2}{*}{$\begin{array}{l}\mathrm{T}=0.969 \\
\mathrm{p}=0.334\end{array}$} \\
\hline Female & $54.89 \pm 15.03$ & \\
\hline \multicolumn{3}{|l|}{ Age group } \\
\hline$<30$ & $70.83 \pm 8.33$ & \multirow{5}{*}{$\begin{array}{l}F=6.715 \\
p=0.000\end{array}$} \\
\hline $30-39$ & $68.75 \pm 12.31$ & \\
\hline $40-49$ & $61.39 \pm 16.40$ & \\
\hline $50-59$ & $56.06 \pm 12.97$ & \\
\hline$\geq 60$ & $51.34 \pm 14.66$ & \\
\hline \multicolumn{3}{|l|}{ Level of education } \\
\hline Unfinished primary & $44.79 \pm 13.58$ & \multirow{4}{*}{$\begin{array}{c}F=7.958 \\
p=0.000\end{array}$} \\
\hline Primary & $51.67 \pm 13.61$ & \\
\hline Secondary & $59.84 \pm 14.35$ & \\
\hline High/college & $60.27 \pm 13.39$ & \\
\hline
\end{tabular}

The highest percentage of respondents said that they "a moderate amount" (45.3\%) and "very much" (12.7\%) enjoy life, male in slightly higher percentage (46.0\% "moderate" and $13.8 \%$ "very much") in relation to female (44.4\% "moderate" and 11.1\% "very much") but without statistically significant difference. More than a half (55.4\%) of respondents said they "very much" and "extremely" feel life is meaningful, in slightly higher percentage male (43.7\% "very much" and $14.9 \%$ "extremely"), but without statistically significant difference compared to female (36.5\% "very much" and $14.3 \%$ "extremely"). "A moderate" ability to concentrate have $2 / 3$ of respondents (33.3\%) and (37.3\%) of them have "very much" ability to concentrate, in a slightly higher percentage male, but without statistically significant difference compared to female. Nearly three-quarters of respondents (74\%) were able to accept their physical appearance, "mostly" (43.3\%) and "completely" (30.7\%). Male were in higher percentage able to accept their physical appearance (43.7\% "mostly" and 33.3\% "completely") than female (42.9\% of "mostly", and $27.0 \%$ "completely") but without statistically significant difference. More than $1 / 2$ of the respondents were "satisfied" $(43.3 \%)$ and "very satisfied" $(10.7 \%)$ with themselves in greater percentage male compared to female respondents, but without statistically significant difference. Negative feelings, such as blue mood, despair, anxiety, depression were present "quite often" (32.7), "very often" (11.3\%) and "always" (4.0\%) in a slightly higher percentage in female but without statistically significant difference compared to male respondents (Table 3).

Younger patients to the question "how much do you enjoy in life", responded with "very much" and "an extreme amount" with a statistically significant difference $(\mathrm{p}=0.001)$ compared to $42 \%$ of older respondents who have answered "not at all" and "a little". To the question "to what extent do you feel life to be meaningful" $1 / 2$ (50\%) of younger respondents answered "very much" and more than $1 / 3$ of them answered "extremely" with statistically significant difference $(p=0.050)$ compared to $19.3 \%$ of those with and over 60 years who responded "not at all" and "little". Ability to concentrate the majority of younger respondents assessed "very much" and "extremely" with statistically significant difference $(p=0.003)$ compared to more than $1 / 5(20 \%)$ of older respondents who assessed their ability to concentrate with "not at all" and "little". Younger respondents "mostly" and "completely" can accept their bodily appearance with a statistically significant difference $(p=0.015)$ compared to $16.2 \%$ of older respondents who answered "not at all" and "little". A high percentage of younger patients were "satisfied" and "very satisfied" with themselves with statistically significant difference $(\mathrm{p}=0.011)$ compared to those with and over 60 years of age. Negative emotions, such as blue mood, despair, anxiety, depression, "seldom" had a $87.5 \%$ of patients younger than 30 years, but without statistically significant difference $(p=0.387)$ in comparison to $45.1 \%$ of the patients with and over 60 years, who said they "quite often", "very often" and "always" have these negative feelings (Table 4). 
Table 3. Answers of patients on questions regarding the psychological domain of quality of life by gender.

\begin{tabular}{|c|c|c|c|c|c|}
\hline \multirow[b]{2}{*}{$\begin{array}{l}\text { Questions of the } \\
\text { psychological domain }\end{array}$} & \multirow[b]{2}{*}{ Answers } & \multirow[b]{2}{*}{$\begin{array}{c}\text { Total } \\
(\mathrm{n}=150) \\
(\%)\end{array}$} & \multicolumn{2}{|c|}{ Gender } & \multirow[b]{2}{*}{$\begin{array}{l}\text { Mann-Whitney } \\
\text { test }\end{array}$} \\
\hline & & & $\begin{array}{c}\text { Male } \\
(\mathrm{n}=87) \\
(\%)\end{array}$ & $\begin{array}{c}\text { Female } \\
(\mathrm{n}=63) \\
(\%)\end{array}$ & \\
\hline \multirow{5}{*}{$\begin{array}{c}\text { How much do you enjoy } \\
\text { life? }\end{array}$} & Not at all & 14.7 & 11.5 & 19.0 & \multirow{5}{*}{$\begin{array}{c}2462.5 \\
p=0.262\end{array}$} \\
\hline & A little & 21.3 & 21.8 & 20.6 & \\
\hline & A moderate amount & 45.3 & 46.0 & 44.4 & \\
\hline & Very much & 12.7 & 13.8 & 11.1 & \\
\hline & An extreme amount & 6.0 & 6.9 & 4.8 & \\
\hline \multirow{5}{*}{$\begin{array}{l}\text { To what extent do you feel } \\
\text { life to be meaningful? }\end{array}$} & Not at all & 0.7 & 0.0 & 1.6 & \multirow{5}{*}{$\begin{array}{c}2595.5 \\
p=0.561\end{array}$} \\
\hline & A little & 14.7 & 16.1 & 12.7 & \\
\hline & A moderate amount & 29.3 & 25.3 & 34.9 & \\
\hline & Very much & 40.7 & 43.7 & 36.5 & \\
\hline & Extremely & 14.7 & 14.9 & 14.3 & \\
\hline \multirow{5}{*}{$\begin{array}{l}\text { How well are you able to } \\
\text { concentrate? }\end{array}$} & Not at all & 3.3 & 2.3 & 4.8 & \multirow{5}{*}{$\begin{array}{c}2443 \\
p=0.234\end{array}$} \\
\hline & A little & 17.3 & 16.1 & 19.0 & \\
\hline & A moderate amount & 33.3 & 32.2 & 34.9 & \\
\hline & Very much & 37.3 & 39.1 & 34.9 & \\
\hline & Extremely & 8.7 & 10.3 & 6.3 & \\
\hline \multirow{5}{*}{$\begin{array}{l}\text { Are you able to accept your } \\
\text { bodily appearance? }\end{array}$} & Not at all & 4.0 & 3.4 & 4.8 & \multirow{5}{*}{$\begin{array}{c}2503.5 \\
p=0.338\end{array}$} \\
\hline & A little & 9.3 & 10.3 & 7.9 & \\
\hline & Moderately & 12.7 & 9.2 & 17.5 & \\
\hline & Mostly & 43.3 & 43.7 & 42.9 & \\
\hline & Completely & 30.7 & 33.3 & 27.0 & \\
\hline \multirow{4}{*}{$\begin{array}{c}\text { How satisfied are you with } \\
\text { yourself? }\end{array}$} & Very dissatisfied & 0.0 & 0.0 & 0.0 & \multirow{5}{*}{$\begin{array}{c}2634 \\
p=0.667\end{array}$} \\
\hline & Dissatisfied & 18.0 & 17.2 & 19.0 & \\
\hline & $\begin{array}{l}\text { Neither satisfied nor } \\
\text { dissatisfied }\end{array}$ & 28.0 & 27.6 & 28.6 & \\
\hline & Satisfied & 43.3 & 43.7 & 42.9 & \\
\hline \multirow{6}{*}{$\begin{array}{l}\text { How often do you have } \\
\text { negative feelings, such as } \\
\text { blue mood, despair, anxiety, } \\
\text { depression? }\end{array}$} & Very satisfied & 10.7 & 11.5 & 9.5 & \\
\hline & Never & 9.3 & 12.6 & 4.8 & \multirow{5}{*}{$\begin{array}{c}2568.5 \\
p=0.486\end{array}$} \\
\hline & Seldom & 42.7 & 40.2 & 46.0 & \\
\hline & Quite often & 32.7 & 32.2 & 33.3 & \\
\hline & Very often & 11.3 & 11.5 & 11.1 & \\
\hline & Always & 4.0 & 3.4 & 4.8 & \\
\hline
\end{tabular}

Most patients with unfinished primary education (75\%) stated that they "not at all" and "a little" enjoy life with a statistically significant difference $(\mathrm{p}=0.001)$ compared to $1 / 3(32.1 \%)$ of respondents with higher education who responded that they "very much" enjoy life. More than 1/3 (40\%) patients with unfinished primary education "not at all" and "a little" can concentrate with a statistically significant difference $(p=0.013)$ compared to more than $1 / 2$ (53.5\%) of respondents with higher education who assessed their ability to concentrate with "very much" and "extremely". Patients without primary education "not at all" and "a little" were able to accept their appearance with a statistically significant difference $(\mathrm{p}=0.003)$ compared to those with higher education who answered "mostly" and "completely". Nearly $1 / 2$ of respondents with unfinished primary education were "dissatisfied" with themselves with a statistically significant difference $(p=0.000)$ compared to those with higher education who were $50 \%$ "satisfied" and $14.3 \%$ "very satisfied" with themselves. That their lives had "not at all" and "a little" sense considered more than 1/3 (35\%) patients without primary education, but without 
statistically significant difference $(p=0.079)$ compared to more than $1 / 2(60.7 \%)$ of respondents with higher education who believe that their life have "very much" and "extremely" sense. Negative feelings have "very often" and "always" $30 \%$ of patients without primary education, but without statistically significant difference (p $=0.376$ ) compared to $60.7 \%$ of patients with higher education that "never" or "seldom" have negative feelings (Table 5).

\section{Discussion}

In patients with diabetes mellitus, in our study, mean score for the psychological domain of quality of life was lower (mean score $56.28 \pm 14.88$ ) than in patients with diabetes mellitus in studies in Denmark (mean score 71.2) [21] and Emirates (mean score $61.5 \pm 13.7$ ) [22], and higher than in studies in Serbia (mean score $55.26 \pm 19.2$ ) [23], Iran (55.67 \pm 11.96 ) [24], as well in African-Americans in Maryland, followed by the SF - 36 (mean score $69 \pm 21)[25]$.

Table 4. Answers of patients on questions regarding the psychological domain of quality of life by age group.

\begin{tabular}{|c|c|c|c|c|c|c|c|}
\hline \multirow{2}{*}{$\begin{array}{l}\text { Questions of the } \\
\text { psychological domain }\end{array}$} & \multirow{2}{*}{ Answers } & \multicolumn{5}{|c|}{ Age group (\%) } & \multirow{2}{*}{$\begin{array}{c}\text { Kruskal Wallis } \\
\text { test }\end{array}$} \\
\hline & & $<30$ & $30-39$ & $40-49$ & $50-59$ & $\leq 60$ & \\
\hline \multirow{5}{*}{$\begin{array}{l}\text { How much do you enjoy } \\
\text { life? }\end{array}$} & Not at all & 0.0 & 0.0 & 0.0 & 16.4 & 21.0 & \multirow{5}{*}{$\begin{array}{c}18.648 \\
\mathrm{p}=0.001\end{array}$} \\
\hline & A little & 0.0 & 10.0 & 33.3 & 23.6 & 21.0 & \\
\hline & A moderate amount & 62.5 & 30.0 & 33.3 & 47.3 & 46.8 & \\
\hline & Very much & 25.0 & 30.0 & 13.3 & 10.9 & 9.7 & \\
\hline & An extreme amount & 12.5 & 30.0 & 20.0 & 1.8 & 1.6 & \\
\hline \multirow{5}{*}{$\begin{array}{l}\text { To what extent do you feel } \\
\text { life to be meaningful? }\end{array}$} & Not at all & 0.0 & 0.0 & 0.0 & 0.0 & 1.6 & \multirow{5}{*}{$\begin{array}{c}9.485 \\
\mathrm{p}=0.050\end{array}$} \\
\hline & A little & 0.0 & 20.0 & 13.3 & 12.7 & 17.7 & \\
\hline & A moderate amount & 12.5 & 0.0 & 33.3 & 30.9 & 33.9 & \\
\hline & Very much & 50.0 & 50.0 & 26.7 & 43.6 & 38.7 & \\
\hline & Extremely & 37.5 & 30.0 & 26.7 & 12.7 & 8.1 & \\
\hline \multirow{5}{*}{$\begin{array}{c}\text { How well are you able to } \\
\text { concentrate? }\end{array}$} & Not at all & 0.0 & 0.0 & 6.7 & 1.8 & 4.8 & \multirow{5}{*}{$\begin{array}{c}15.686 \\
\mathrm{p}=0.003\end{array}$} \\
\hline & A little & 0.0 & 0.0 & 20.0 & 21.8 & 17.7 & \\
\hline & A moderate amount & 12.5 & 20.0 & 20.0 & 29.1 & 45.2 & \\
\hline & Very much & 62.5 & 60.0 & 26.7 & 41.8 & 29.0 & \\
\hline & Extremely & 25.0 & 20.0 & 26.7 & 5.5 & 3.2 & \\
\hline \multirow{5}{*}{$\begin{array}{l}\text { Are you able to accept } \\
\text { your bodily appearance? }\end{array}$} & Not at all & 0.0 & 0.0 & 0.0 & 3.6 & 6.5 & \multirow{5}{*}{$\begin{array}{c}12.310 \\
p=0.015\end{array}$} \\
\hline & A little & 0.0 & 0.0 & 13.3 & 10.9 & 9.7 & \\
\hline & Moderately & 0.0 & 10.0 & 0.0 & 12.7 & 17.7 & \\
\hline & Mostly & 37.5 & 40.0 & 40.0 & 43.6 & 45.2 & \\
\hline & Completely & 62.5 & 50.0 & 46.7 & 29.1 & 21.0 & \\
\hline \multirow{5}{*}{$\begin{array}{c}\text { How satisfied are you with } \\
\text { yourself? }\end{array}$} & Very dissatisfied & 0.0 & 0.0 & 0.0 & 0.0 & 0.0 & \multirow{5}{*}{$\begin{array}{c}13.105 \\
p=0.011\end{array}$} \\
\hline & Dissatisfied & 0.0 & 10.0 & 20.0 & 14.5 & 24.2 & \\
\hline & $\begin{array}{l}\text { Neither satisfied nor } \\
\text { dissatisfied }\end{array}$ & 0.0 & 20.0 & 33.3 & 29.1 & 30.6 & \\
\hline & Satisfied & 62.5 & 50.0 & 33.3 & 45.5 & 40.3 & \\
\hline & Very satisfied & 37.5 & 20.0 & 13.3 & 10.9 & 4.8 & \\
\hline \multirow{5}{*}{$\begin{array}{l}\text { How often do you have } \\
\text { negative feelings, such as } \\
\text { blue mood, despair, } \\
\text { anxiety, depression? }\end{array}$} & Never & 0.0 & 0.0 & 6.7 & 7.3 & 14.5 & \multirow{5}{*}{$\begin{array}{c}4.145 \\
p=0.387\end{array}$} \\
\hline & Seldom & 87.5 & 40.0 & 33.3 & 41.8 & 40.3 & \\
\hline & Quite often & 12.5 & 60.0 & 40.0 & 32.7 & 29.0 & \\
\hline & Very often & 0.0 & 0.0 & 13.3 & 12.7 & 12.9 & \\
\hline & Always & 0.0 & 0.0 & 6.7 & 5.5 & 3.2 & \\
\hline
\end{tabular}


Table 5. Answers of patients on questions regarding the psychological domain of quality of life by level of education.

\begin{tabular}{|c|c|c|c|c|c|c|}
\hline \multirow[b]{2}{*}{$\begin{array}{l}\text { Questions of the psychological } \\
\text { domain }\end{array}$} & \multirow[b]{2}{*}{ Answers } & \multicolumn{4}{|c|}{ Level of education (\%) } & \multirow[b]{2}{*}{ Kruskal Wallis test } \\
\hline & & 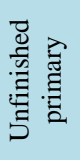 & 悹 & 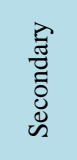 & 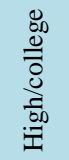 & \\
\hline \multirow{5}{*}{ How much do you enjoy life? } & Not at all & 35.0 & 16.7 & 12.5 & 3.6 & \multirow{5}{*}{$\begin{array}{c}17.574 \\
p=0.001\end{array}$} \\
\hline & A little & 40.0 & 16.7 & 20.8 & 14.3 & \\
\hline & A moderate amount & 20.0 & 60.0 & 44.4 & 50.0 & \\
\hline & Very much & 0.0 & 6.7 & 11.1 & 32.1 & \\
\hline & An extreme amount & 5.0 & 0.0 & 11.1 & 0.0 & \\
\hline \multirow{4}{*}{$\begin{array}{c}\text { To what extent do you feel life } \\
\text { to be meaningful? }\end{array}$} & Not at all & 5.0 & 0.0 & 0.0 & 0.0 & \multirow{5}{*}{$\begin{array}{c}6.801 \\
p=0.079\end{array}$} \\
\hline & A little & 30.0 & 13.3 & 13.9 & 7.1 & \\
\hline & A moderate amount & 25.0 & 43.3 & 23.6 & 32.1 & \\
\hline & Very much & 35.0 & 30.0 & 44.4 & 46.4 & \\
\hline \multirow{6}{*}{$\begin{array}{c}\text { How well are you able to } \\
\text { concentrate? }\end{array}$} & Extremely & 5.0 & 13.3 & 18.1 & 14.3 & \\
\hline & Not at all & 10.0 & 3.3 & 1.4 & 3.6 & \multirow{5}{*}{$\begin{array}{c}10.851 \\
p=0.013\end{array}$} \\
\hline & A little & 30.0 & 20.0 & 18.1 & 3.6 & \\
\hline & A moderate amount & 30.0 & 46.7 & 26.4 & 39.3 & \\
\hline & Very much & 30.0 & 30.0 & 38.9 & 46.4 & \\
\hline & Extremely & 0.0 & 0.0 & 15.3 & 7.1 & \\
\hline \multirow{5}{*}{$\begin{array}{l}\text { Are you able to accept your } \\
\text { bodily appearance? }\end{array}$} & Not at all & 15.0 & 3.3 & 1.4 & 3.6 & \multirow{5}{*}{$\begin{array}{c}14.231 \\
p=0.003\end{array}$} \\
\hline & A little & 15.0 & 13.3 & 8.3 & 3.6 & \\
\hline & Moderately & 15.0 & 26.7 & 9.7 & 3.6 & \\
\hline & Mostly & 40.0 & 40.0 & 43.1 & 50.0 & \\
\hline & Completely & 15.0 & 16.7 & 37.5 & 39.3 & \\
\hline \multirow{5}{*}{$\begin{array}{c}\text { How satisfied are you with } \\
\text { yourself? }\end{array}$} & Very dissatisfied & 0.0 & 0.0 & 0.0 & 0.0 & \multirow{5}{*}{$\begin{array}{c}18.688 \\
p=0.000\end{array}$} \\
\hline & Dissatisfied & 45.0 & 26.7 & 9.7 & 10.7 & \\
\hline & $\begin{array}{l}\text { Neither satisfied nor } \\
\text { dissatisfied }\end{array}$ & 25.0 & 40.0 & 25.0 & 25.0 & \\
\hline & Satisfied & 30.0 & 26.7 & 51.4 & 50.0 & \\
\hline & Very satisfied & 0.0 & 6.7 & 13.9 & 14.3 & \\
\hline \multirow{5}{*}{$\begin{array}{l}\text { How often do you have negative } \\
\text { feelings, such as blue mood, } \\
\text { despair, anxiety, depression? }\end{array}$} & Never & 15.0 & 3.3 & 8.3 & 14.3 & \multirow{5}{*}{$\begin{array}{c}3.104 \\
p=0.376\end{array}$} \\
\hline & Seldom & 30.0 & 40.0 & 45.8 & 46.4 & \\
\hline & Quite often & 25.0 & 43.3 & 30.6 & 32.1 & \\
\hline & Very often & 20.0 & 10.0 & 11.1 & 7.1 & \\
\hline & Always & 10.0 & 3.3 & 4.2 & 0.0 & \\
\hline
\end{tabular}

In our study, mean score of psychological domain of quality of life were higher in male compared to female respondents, but without statistically significant difference. The mean score for this domain of health was statistically significantly higher for male in the study Martinez et al. [26], as well as in the study Pal et al. [27] where the female had a statistically significant lower mean score on a psychological scale. Also in the study in Turkey [28] the mean score for psychological domain was statistically significant lower in female. Statistically significant differences were not found in the mean scores of psychological domain in relation to sex in studies in Nigeria [29] and Benin [7].

In relation to the age group of patients with diabetes mellitus in our study, the highest mean score for psychological domain were observed in patients younger than 30 years, and with increase of age there was a statistically significant decline in the mean score of psychological domain of health. 
In a survey in the Gaza Strip [30], which was conducted among people living in exile, age strongly influenced on quality of life in patients with diabetes mellitus in the psychological domain, while age almost did not affected the quality of life in patients without diabetes mellitus. Patients with diabetes mellitus younger than 50 years had a better quality of life than older patients [30]. In patients of mean age $70.0 \pm 9.9$ years in the study in Greek was not found statistically significant association in the field of psychological health in relation to the age [31]. In patients with type 2 diabetes there was no statistically significant correlation between psychological domain and age in the study by Martinez et al. [26] and study Pala et al. [27].

The connection between psychological domain of health and age was not found in the study in Iran [24] as well as in study in Nigeria [29]. In a study in Mexican Americans with or without diabetes was evaluated quality of life of an elderly person $(\mathrm{Me}=77.26)$ and the highest score was for the domain of mental health with no statistically significant difference compared to control without diabetes mellitus [32].

In our study, in patients with diabetes mellitus was observed a correlation between level of education and psychological domain of health. Mean scores of psychological domain were lowest in patients with unfinished primary school, and with increase of level of education, with a statistically significant difference, there was an increase in scores of psychological health domain so that the mean score were highest in patients with high education.

In a study in Iran [24] educated patients had better quality of life in all scales. Martinez et al. [26] found a connection between the psychological domain with the level of education, the mean score in each of the domains of quality of life has increased with increasing level of education. The level of education has not shown a significant association with psychological domain in study Pala et al. [27] as well as in a study in Nigeria [29].

More than a $1 / 2$ (58\%) of the respondents in our study said that they enjoy in life, "a moderate amount" (45.3\%) and "very much" (12.7\%) in contrast to the study by Eljedi in the Gaza Strip [33], which has questioned the quality of life in patients with diabetes mellitus (refugees and non refugees) where 67\% of those who are not refugees stated that "very much" and "an extreme amount” enjoy life [33]. That their life is meaningful "very much" and "extremely" in our survey said more than a half of (55.5\%) patients, which was less than in the study by Eljedi [31], in which 2/3 (73\%) patients with diabetes mellitus who are not refugees reported that their life “very much" and "extremely” makes sense. That life has meaning "very much" and “extremely” answered 80\% of patients in a study in Brazil [34] in which participated 50 patients with and 50 patients without diabetes mellitus.

In a study by Eljedi [33] people with diabetes mellitus who were not refugees in slightly higher percentage (60\%) in relation to our study (46\%), were able to "very much" and "extremely" concentrate.

Their physical appearances in our study "mostly” and “completely” were able to accept (74\%) of patients, and more than 1/2 of them said they were "satisfied” and "very satisfied” with themselves. In study by Eljedi [33] 59\% of people with diabetes mellitus who were not refugees were "mostly" and "completely" satisfied with their bodily appearance, and $73 \%$ of them were "satisfied" or "very satisfied” with themselves.

In a slightly higher percentage (86\%) then in our study respondents in study Beltrame [34] were able to "mostly" and "completely" accept their appearance, and 88\% were "satisfied" and "very satisfied" with themselves. More than 1/2 (52\%) of the respondents in our study said that they "never" and "seldom” have negative feelings such as blue mood, despair, anxiety and depression which is in compliance with study by Eljedi where $58 \%$ of diabetes non-refugees "never" and "seldom” have negative feelings [33] and less than study by Beltrame [34] in which $92 \%$ of patients with diabetes "never" and "seldom” have negative feelings. In patients with diabetes mellitus was observed a correlation between level of education and psychological domain of health in our study. Most patients with unfinished primary education "not at all” and “a little” enjoy life, "not at all” and "a little” can concentrate, "not at all” and "a little” were able to accept their appearance, they were dissatisfied with themselves with a statistically significant difference compared with patients with a higher level of education. Negative feelings such as blue mood, despair, anxiety and depression were more prevalent in people without primary education, but without statistically significant difference.

Similar results were shown by studies in Iran [24] where educated patients had higher mean scores for psychological domain of quality of life.

Martinez with associates [26] found a connection between the psychological domain and the level of education, and the mean score increased with increasing levels of education. Our finding is not in line with a study Pala et al. [27] where the level of education did not show a significant association with psychological domain.

In a study conducted in Iran, patients with duration of education longer than 12 years reported significantly 
fewer problems in the dimension anxiety/depression than those with a shorter duration of education [35]. In the domain of anxiety/depression in a study in Korea [36], patients in the elementary school or below group had lower EQ-5D index scores than those in the middle/high school and university or above groups. People with longer duration of education reported statistically significant higher mean score in the field of mental health in a study in Greece [31], while in a study in Nigeria [29] there was no significant correlation between quality of life and level of education.

\section{Conclusions}

The mean score of quality of life for the domain of psychological health statistically and significantly decreased with increasing of age, and statistically and significantly increased with an increase of level of education. Negative feelings such as blue mood, despair, anxiety and depression, were present in investigated patients without statistically significant difference in relation to sex, age and level of education.

To provide a complete evaluation of quality of life changes in this domain, it is necessary to examine the changes in mood and level of depression in patients with diabetes mellitus and their impact on the self-regulation of sugar. To estimate the true image of the psychological domain of quality of life, it would be good to examine the impact of support that they have/or not have from their family, the workplace, the community and society in general with regard to negative psychological feelings.

Age and level of education affect the psychological domain of quality of life of people with diabetes mellitus. Negative feelings associated with this disease are present in all patients in relation to socio-demographic variables (gender, age and level of education). This points the need for preventive action in dealing with persons suffering from diabetes mellitus to soften and reduce these negative feelings.

\section{References}

[1] World Health Organization (2012) Chronic Disease. WHO, Copenhagen.

[2] Devins, G.M. and Binik, Y.M. (1996) Facilitating Coping with Chronic Physical Illness. In: Zeidner, M. and Endler, N., Eds., Handbook of Coping: Theory, Research and Applications, Wiley, New York, 640-696.

[3] Moos, R.H. and Schaeffer, J.A. (1984) The Crisis of Physical Illness. An Overview and Conceptual Approach. In: Moss, R.M., Ed., Coping with Physical Illness, New Perspectives, Plenum Press, New York, 3-39.

[4] Sigurdardottir, A.K., Bendiktsson, R. and Jonsdottir, H. (2009) Instruments to Tailor Care of People with Type 2 Diabetes. Journal of Advanced Nursing, 65, 2119-2130. http://dx.doi.org/10.1111/j.1365-2648.2009.05040.x

[5] Rubin, R.R. (2000) Diabetes and Quality of Life. Diabetes Spectrum, 13, 2000-2021.

[6] Snoek, F.J., Welch, G.R., Pouwer, F. and Polonsky, W.H. (2000) Diabetes-Related Emotional Distress in Dutch and US Diabetic Patients. Diabetes Care, 23, 1305-1309. http://dx.doi.org/10.2337/diacare.23.9.1305

[7] Odili, V., Ugboka, L. and Oparah, A. (2010) Quality of Life of People with Diabetes in Benin City as Measured with WHOQOL-BREF. The Internet Journal of Law, Healthcare and Ethics, 6, 2.

[8] Polonsky, W. (2000) Understanding and Assessing Diabetes-Specific Quality of Life. Diabetes Spectrum, $13,36$.

[9] Mosnier-Pudar, H., Hochberg, G., Eschwege, E., Halimi, S., Virally, M.L., Guillausseau, P.J., et al. (2010) How Patients' Attitudes and Opinions Influence Self-Care Behaviors in Type 2 Diabetes. Insights from the French DIABASIS Survey. Diabetes Metabolism, 36, 476-483. http://dx.doi.org/10.1016/j.diabet.2010.08.004

[10] Reddy, J., Wilhelm, K. and Campbell, L. (2013) Putting PAID to Diabetes-Related Distress: The Potential Utility of the Problem Areas in Diabetes (PAID) Scale in Patients with Diabetes. Psychosomatics, 54, 44-51. http://dx.doi.org/10.1016/j.psym.2012.08.004

[11] Zagarins, S.E., Allen, N.A., Garb, J.L. and Welch, G. (2012) Improvement in Glycemic Control Following a Diabetes Education Intervention Is Associated with Change in Diabetes Distress but Not Change in Depressive Symptoms. Journal of Behavioral Medicine, 35, 299-304. http://dx.doi.org/10.1007/s10865-011-9359-z

[12] Fidler, C., Elmelund Christensen, T. and Gillard, S. (2011) Hypoglycemia: An Overview of Fear of Hypoglycemia, Quality-of-Life, and Impact on Costs. Journal of Medical Microbiology, 14, 646-655. http://dx.doi.org/10.3111/13696998.2011.610852

[13] Guyatt, G.H., Feeny, D.H. and Patrick, D.L. (1993) Measuring Health-Related Quality of life. Annals of Internal Medicine, 118, 622-629. http://dx.doi.org/10.7326/0003-4819-118-8-199304150-00009

[14] Guyatt, G.H., Thompson, P.J., Berman, L.B., et al. (1985) How Should We Measure Function in Patients with Chronic Heart and Lung Disease? Journal of Chronic Disease, 38, 517-524. http://dx.doi.org/10.1016/0021-9681(85)90035-9 
[15] Wennberg, J.E. (1990) Outcomes Research, Cost Containment, and the Fear of Health Care Rationing. New England Journal of Medicine, 323, 1202-1204. http://dx.doi.org/10.1056/NEJM199010253231710

[16] Brown, G.C., Brown, M.M., Sharma, S., Brown, H., Gozum, M. and Denton, P. (2000) Quality of Life Associated with Diabetes Mellitus in an Adult Population. Journal of Diabetes and Its Complications, 14, 18-24. http://dx.doi.org/10.1016/S1056-8727(00)00061-1

[17] Issa, B.A., Yussuf, A.D. and Baiyewu, O. (2007) The Association between Psychiatric Disorders and Quality of Life of Patient with Diabetes Mellitus. Iranian Journal of Psychiatry, 2, 30-34.

[18] Gavric, Z. (2014) The Impact of Breast Cancer on the Emotional Component of Health. International Neuropsychiatric Disease Journal, 2, 104-114.

[19] The World Health Organization (2005) The World Health Organization Quality of Life (WHOQOL)—BREF. WHO, Geneva.

[20] The World Health Organization (2006) WHOQOL User Manual. WHO, Geneva.

[21] Nørholm, V. and Bech, P. (2001) The WHO Quality of Life (WHOQOL) Questionnaire: Danish Validation Study. Nordic Journal of Psychiatry, 55, 229-235. http://dx.doi.org/10.1080/080394801681019075

[22] Bani-Issa, W. (2011) Evaluation of the Health-Related Quality of Life of Emirati People with Diabetes: Integration of Socio-Demographic and Disease-Related Variables. EMHJ, 17, 825-830.

[23] Bosić-Živanović, D., Medić-Stojanoska, M. and Kovačev-Zavišić, B. (2012) The Quality of Life in Patients with Diabetes Mellitus Type 2. Vojnosanitetski Pregled, 69, 858-863.

[24] Aghamollaei, T., Eftekhar, H., Shojaeizadeh, D., Mohammad, K., Nakhjavani, M. and Pour, F.G. (2003) Behavior, Metabolic Control and Health-Related Quality of Life in Diabetic Patients at Bandar Abbas Diabetic Clinic. Iranian Journal of Public Health, 32, 54-59.

[25] Hill-Briggs, F., Gary, T.L., Hill, M.N., Bone, L.R. and Brancati, F.L. (2002) Health-Related Quality of Life in Urban African Americans with Type 2. Journal of General Internal Medicine, 17, 412-419. http://dx.doi.org/10.1046/j.1525-1497.2002.11002.x

[26] Martínez, V.Y., Prado-Aguilar, A.C., Rascón-Pacheco, A.R. and Valdivia-Martínez, J.J. (2008) Quality of Life Associated with Treatment Adherence in Patients with Type 2 Diabetes: A Cross-Sectional Study 2008. BMC Health Services Research, 8, 164. http://dx.doi.org/10.1186/1472-6963-8-164

[27] Pala, T., Eser, E., Özmen, B., Aydemir, O. and Boyvoda, S. (2004) The Determinants of Quality of Life Including Treatment Satisfaction in Patients with Type Two Diabetes Mellitus: Are Different Generic Qol Instruments Sensitive to the Same Determinants? Turkish Journal of Endocrinology and Metabolism, 3, 91-99.

[28] Saatcioğlu, O., Çelikel, F. C., Kutlutürk, F., ElbozanCumurcu, B., Kisacik, B., Yildiz, S. and Erim, R. (2008) Disability and Quality of Life in Patients with Type 2 Diabetes Mellitus. Anatolian Journal of Clinical Investigation, 2, 106-112.

[29] Kolawole, B.A., Mosaku, S.K. and Ikem, R.T. (2009) A Comparison of Two Measures of Quality of Life of Nigerian Clinic Patients with Type 2 Diabetes Mellitus. African Health Sciences, 9, 161-166.

[30] Eljedi, A., Mikolajczyk, R., Kraemer, A. and Laaser, U. (2006) Health-Related Quality of Life in Diabetic Patients and Controls without Diabetes in Refugee Camps in the Gaza Strip: A Cross-Sectional Study. BMC Public Health, 6, 268. http://dx.doi.org/10.1186/1471-2458-6-268

[31] Papadopoulos, A.A., Kontodimopoulos, N., Frydas, A., Ikonomakis, E. and Niakas, D. (2007) Predictors of Health-Related Quality of Life in Type II Diabetic Patients in Greece. BMC Public Health, 7, 186. http://dx.doi.org/10.1186/1471-2458-7-186

[32] Graham, J.E., Stoebner-May, D.G., Ostir, G.V., Snih, S.A., Peek, M.K., Markides, K. and Ottenbacher, K.J. (2007) Health Related Quality of Life in Older Mexican Americans with Diabetes: A Cross-Sectional Study. Health Quality Life Outcomes, 5, 39. http://dx.doi.org/10.1186/1477-7525-5-39

[33] Eljedi, A.Y. (2005) Diabetes Mellitus and Quality of Life of the Palestinian Diabetic Refugees in the Refugee Camps in Gaza Strip. Dissertation, Bielefeld University, Bielefeld.

[34] Beltrame, V. (2008) Qualidade de vida de idososdiabéticos. Dissertation, Pontifícia Universidade Católica do Rio Grande do Sul, Porto Alegre, Instituto de Geriatria e Gerontologia.

[35] Javanbakht, M., Abolhasani, F., Mashayekhi, A., Baradaran, H.R. and Noudeh, Y.J. (2012) Health Related Quality of Life in Patients with Type 2 Diabetes Mellitus in Iran: A National Survey. PLoS ONE, 7, e44526. http://dx.doi.org/10.1371/journal.pone.0044526

[36] Lee, W.J., Song, K.H., Noh, J.H., Choi, Y.J., and Jo, M.W. (2012) Health-Related Quality of Life Using the EuroQol 5D Questionnaire in Korean Patients with Type 2 Diabetes. Journal of Korean Medical Science, 27, 255-260. http://dx.doi.org/10.3346/jkms.2012.27.3.255 